Tropical Journal of Pharmaceutical Research April 2015; 14 (4): 701-705

ISSN: $1596-5996$ (print); 1596-9827 (electronic)

(C) Pharmacotherapy Group, Faculty of Pharmacy, University of Benin, Benin City, 300001 Nigeria.

All rights reserved.

Available online at http://www.tjpr.org

Original Research Article

http://dx.doi.org/10.4314/tjpr.v14i4.20

\title{
Psychometric Validation of Stress and Compliance Scale for Diabetes (SCSD) in Penang, Malaysia
}

\author{
S Wasif Gillani ${ }^{1 *}$, Syed Azhar Syed $\mathrm{S}^{2}$, Diana Laila Rahmatillah ${ }^{3}$ and Mirza Baig ${ }^{4}$ \\ ${ }^{1}$ School of Pharmacy, Monash University Sunway Campus, 47500, Bandar Sunway, Selangor, ${ }^{2}$ Discipline of Clinical Pharmacy, \\ School of Pharmaceutical Sciences, Universiti Sains Malaysia (USM), Malaysia, ${ }^{3}$ Faculty of Pharmacy, UTA'45 Jakarta, \\ Indonesia, ${ }^{4}$ Unit of Clinical Pharmacy \& Pharmacy Practice, Dubai Pharmacy College, Dubai
}

*For correspondence: Email: wasifgillani@gmail.com, wasifgillani@monash.edu; Tel: +603-55145882

Received: 19 May 2014

Revised accepted: 23 February 2015

\begin{abstract}
Purpose: To provide factorial analytical findings, and to construct validation and normative data for Malaysian diabetic patients in Penang.

Method: A population-based survey was conducted in Penang, Malaysia during Nov 2012 to March 2013. Cluster random sampling technique was employed for the selection of participants in the community. A total of 1924 diabetic patients of age $\geq 18$ years (mean age $=39.51$ years) were approached; 992 of them were female and 932 male. LISREL 8.30 program was used for assenting factor analysis. Chi-square $\left(X^{2}\right)$ /df (degree of freedom) ratio, GFI (goodness of fit index), AGFI (adjusted goodness of fit index) and root mean square error of approximation (RMSEA) were used to evaluate the fit of the model (two-factor).

Results: Barlett's test of sphericity was $1603.417(p<0.001)$ while Kaiser-Meyer-Olkin measure of sampling adequacy was 0.83 . Varimax rotation was conducted with these two identified factors. Factor A integrated items 1, 2, 3, 6, 9 and 10, labeled as 'Perceived Stress' while Factor B contained items 4, 5, 7, 8 and labeled as 'Perceived Compliance'. Item variance showed $45.73 \%$ of accountability with Factor $A$ and $13.43 \%$ with Factor $B$. Mandatory factor analysis for the two-factor of Malaysian version of $P S S$ yielded: $G F I S X^{2}(39)=127.846, p<0.001, X^{2} / d f=4.1 ; G F I=0.97 ; A G F I=0.96 ; R M S E A=0.06$ and $\mathrm{CFI}=0.99$.

Conclusion: SCSD-10 is a reliable tool for assessing stress and compliance among diabetics living in a society.
\end{abstract}

Keywords: Diabetes mellitus, Malaysia stress scale, Stress and compliance scale for diabetes, Stress, Validation, Factor analysis, Barlett's test, Kaiser-Meyer-Olkin measure

Tropical Journal of Pharmaceutical Research is indexed by Science Citation Index (SciSearch), Scopus, International Pharmaceutical Abstract, Chemical Abstracts, Embase, Index Copernicus, EBSCO, African Index Medicus, JournalSeek, Journal Citation Reports/Science Edition, Directory of Open Access Journals (DOAJ), African Journal Online, Bioline International, Open-J-Gate and Pharmacy Abstracts

\section{INTRODUCTION}

Increase disease burden of diabetes is a thread to medical professionals worldwide, World Health Organization (WHO) estimates a rise of $55 \%$ approx in current (2007) diabetes patients by 2025 [1]. In 2001, 16.7 million adults in the United States were estimated to have been diagnosed with DM [2]. Findings have been equivocal in regards to whether transient or chronic stress interferes with metabolic control [3-8]. Aside from the potential physiological impact, chronic stress may interfere with a person's capacity to adhere to lifestyle factors that are essential to diabetic health. Interrupted sleep also results from chronic stress [9], which is particularly concerning in a diabetic population given recent findings that insufficient quantity and/or poor quality of sleep are associated with obesity and metabolic dysfunction $[10,11]$. 
Although the definitions of stress have varied, it is generally characterized as physiological and psychological consequences that occur when the demands placed on a person exceed their individual and social resources $[11,12]$. How a stressor interacts with individual characteristics in producing certain adaptive or maladaptive outcomes depends on two critical processes that are theorized to mediate the relationship between the environment and individual, cognitive appraisal and coping strategies [13]. Coping responses can alter the effect of a stressor on individual functioning by increasing or decreasing the negative effects of stressors, in turn exacerbating or alleviating related psychological distress $[12,13]$.

It is important to emphasize that stress appraisals are determined not solely by the stimulus condition or the response variables, but rather, by the persons' interpretations of their relationships to their environments $[12,14]$. The only empirically established index of which researchers are aware that falls into the category of general appraisal instrument is the Perceived Stress Scale (PSS) [15]. However the limitation of PSS in the diabetes patients and furthermore there is a need of combined scale for both stress and compliance assessment. The purpose of this study was to provide factorial analytic findings, construct validation and normative data for the Malaysian diabetic patients to Stress and Compliance Scale for Diabetes (SCSD)-10 scale. Gender difference was also examined along with racial response to SCSD-10.

\section{EXPERIMENTAL}

\section{Participants}

A population based survey was conducted in Penang during Nov 2012 to March 2013. Penang is one of the fourteen states located in the northwest of Malaysia and comprises of the mainland and Penang Island. Its population is 1580.0 thousand. Different ethnic groups inhabiting the state are Chinese (46.1\%), Malays $(42.9 \%)$, Indians $(10.6 \%)$, and other minorities $(0.4 \%)[16]$.

Sample size with $50 \%$ response rate, $5 \%$ margin of error and $95 \%$ confidence interval is 239 (1580,000 total population) but literature shows that population based survey must contain a sample of minimum 1500 to 2000 disease population (per 2 - 3 million population). So the study sample size was1924 as per population (1.58 million population).
Cluster random sampling technique was employed for the selection participants in the community. Participants were approached in plazas, malls, shopping marts and invited to take part in this survey. To avoid bias, all the three main ethnic groups were included according to the racial distribution in the country.

\section{Instrument (supplementary file)}

SCSD-10 (self-developed) measures an individual's appraisal of his/her life as stressful (i.e., unpredictable, uncontrollable and overloading). Item examples include, 'how long you are carrying diabetes mellitus?' and 'Rate your life on current life satisfaction scale!' People rated how often they had experienced these feelings in the last week on five-point Likert scale or more specific 10-point evaluation. SCSD-10 scores were obtained by reversing the scores on the four positive compliance items; the items were $4,5,7$ and 8 . Total scores range from 0 to 40, with higher scores indicating noncompliance/nonstatisfactory behavior. Coefficient alpha reliability was 0.86 for a newly diagnosed breast cancer population consistent with alphas from 0.75 to 0.86 in the general literature [17].

The translation of scale into Malay language was done with a qualitative method that is a one-way translation (translation and control of the questionnaire with a different group of translators after inquiry. The scale was translated into Malay language independently by two psychological counselors who had at least a master's degree and bilingual efficiency. Later, center of language and translation (USM) selected the best anonymous version among two translations; also, the researcher and co-researchers compared the match and contrast between the translations. The reconcile version was then back translated to the original language by a native speaker of the English language and fluent in Malay language. Few minor discrepant items were found. Finally, a Malay language teacher reviewed the absolute form and her suggestions were added into the translation. Then, this form was presented to the researcher team working on this project.

\section{Procedure}

Verbal consent was taken from the respondents and instructions were given to fill the questionnaires. All questionnaires were anonymous so to maintain the privacy participants were asked to fold the questionnaire after filling. Ethical approval was obtained from 
the Social and Behavioural Research Ethics Committee, Universiti Sains Malaysia.

\section{Statistical analysis}

LISREL 8.30 program (Scientific Software International Inc, Chicago) was used to conduct factor analysis. A maximum likelihood was used for the estimation method, and the integrated two-factor model was tested. Chi-square $\left(X^{2}\right) / d f$ (degree of freedom) ratio, GFI (goodness of fit index), AGFI (adjusted goodness of fit index) and root mean square error of approximation (RMSEA) were used to evaluate the fit of the model (two-factor). The following criteria were used to indicate goodness of fit: GFI, AGFI and CFI (comparative fit index) 0.90 and higher, RMSEA 0.08 or lower and Chi-square/df ratio 3 or lower [18].

\section{RESULTS}

Principal component factor analysis was done for the analysis of 10 item SCSD dimensionality with a sample of 1924 diabetic patients. Principle determination of factors to rotate based on; hypothesis that the measure was twodimensional, the scree test and the interpretability of the factor solution. A total of 1924 diabetic patients with age $\geq 18$ (mean age = 39.51) were approached, 992 of them were female and 932 of them were male.

Barlett's test of sphericity was 1603.417 ( $p<$ 0.001 ) and Kaiser-Meyer-Olkin measure of the sampling adequacy was 0.83 , which supported the use of these data in a factor analysis for further investigation. Initial analysis yielded two components with Eigenvalues exceeding 1, accumulating the total of 59.16 per cent of the variance. Scree-plot inspection indicated two factors. Varimax rotation was conducted with these two identified factors. Factor $A$ integrated items 1, 2, 3, 6, 9 and 10, labeled as 'Perceived Stress' while Factor B containing items 4, 5, 7, 8 and labeled as 'Perceived Compliance'.

In this study, the newly developed SCSD-10 showed that the Factor A consisted of all the items of negative experiences and the Factor $B$ consisted of all items of positive experiences. But on synchronizing the factor loading, item 5 and 9 both cross loaded onto both factors. Depending on different scope of studies as to establish equivalence and as theoretically item 5 was an item of positive experience so it was incorporated in 'controllable' factor, but item 9 remained in 'stress' factor. Item variance showed $45.73 \%$ of accountability with Factor $A$ and $13.43 \%$ with Factor B. Detailed descriptive information and factor analytical findings for 10 scale items are presented in Table 1.

On the first phase of model evaluation, six items related to 'Stress' were specified to identify with Perceived Stress Factor, and other four 'Compliance' related items were specified to identify with Perceived Compliance. Mandatory factor analysis for the two-factor of SCSD yielded: GFIs: $X^{2}(39)=127.846, p<0.001$, $\mathrm{X}^{2} / \mathrm{df}=4.1 ; \mathrm{GFI}=0.97 ; \mathrm{AGFI}=0.96 ;$ RMSEA = 0.06 and $\mathrm{CFI}=0.99$. This information indicated a good fit but the high $x^{2} /$ df ratio reflects the probability of large sample size. Standard variance values and multiple correlations of the items of SCSD - 10 were presented in Table 2.

Table 1: Varimax-rotated factor loadings, communalities, Eigenvalues, explained variance of Malaysian version of Perceived Stress Scale (2-factor model)

\begin{tabular}{lccccc}
\hline Item no. & Communalities & $\begin{array}{c}\text { Factor A } \\
\text { Stress }\end{array}$ & $\begin{array}{c}\text { Factor B } \\
\text { Compliance }\end{array}$ & M & SD \\
& & & & & \\
\hline 1 & 0.53 & 0.72 & & 2.09 & 0.99 \\
2 & 0.59 & 0.77 & & 1.95 & 1.15 \\
3 & 0.48 & 0.65 & 0.52 & 1.77 & 1.14 \\
5 & 0.55 & 0.60 & & 1.96 & 1.05 \\
6 & 0.51 & 0.70 & 0.45 & 2.37 & 1.03 \\
9 & 0.60 & 0.71 & & 1.41 & 1.17 \\
10 & 0.64 & 0.75 & 0.71 & 1.59 & 0.97 \\
4 & 0.51 & & 0.75 & 2.01 & 0.95 \\
7 & 0.60 & & 0.77 & 1.86 & 0.97 \\
8 & 0.61 & 4.57 & 1.34 & & \\
\hline Eigenvalue & & 45.73 & 13.43 & & \\
\hline
\end{tabular}


Table 2: Multiple correlations of the items of two-factor model

\begin{tabular}{lcccc}
\hline Characteristics & $\boldsymbol{\Lambda}$ & $\mathbf{S E}$ & $\boldsymbol{t}$ & $\mathbf{R}^{\mathbf{2}}$ \\
\hline Perceived Stress & & & & \\
1 & 0.65 & 0.04 & 16.13 & 0.44 \\
2 & 0.73 & 0.05 & 18.21 & 0.57 \\
3 & 0.61 & 0.05 & 13.55 & 0.39 \\
6 & 0.67 & 0.05 & 15.98 & 0.48 \\
9 & 0.63 & 0.05 & 15.31 & 0.40 \\
10 & 0.77 & 0.04 & 20.12 & 0.67 \\
Perceived Compliance & & & & \\
4 & 0.57 & 0.05 & 10.12 & 0.35 \\
5 & 0.79 & 0.05 & 17.27 & 0.59 \\
7 & 0.55 & 0.05 & 11.01 & 0.31 \\
8 & 0.63 & 0.05 & 14.09 & 0.42 \\
\hline
\end{tabular}

The mean [Mean $(M)=19.35]$ and standard deviation [SD $=6.84]$ were computed for the total score and two factors of the scale. Perceived Stress $[\mathrm{M}=11.98 ; \mathrm{SD}=4.82]$ and Perceived Compliance [M = 7.23; SD = 2.09]. Independent sample t-Test was used to identify the difference in between gender in the perception of stress. Findings suggested significant difference between male $(\mathrm{M}=18.67 ; \mathrm{SD}=5.13)$ and female $(M=21.37$; $S D=7.24)$ on the SCSD -10 and the total score, $(\mathrm{t}(1924)=3.91, p<0.001)$. One way ANOVA computed no significant $(p<$ 0.91) difference of perceived stress among different races.

Cronbach's alpha reliability coefficients for the SCSD - 10 were: SCSD - 10 total score (ten items; 0.81); Perceived Stress factor (six items; 0.87 ) and Perceived Compliance (four items; $0.75)$. Finally the correlation analysis with total Perceived stress score to Factor A $(0.71, p<$ $0.01)$ and Factor $B(0.49, p<0.01)$ indicating that subjects with more health complaints have higher level of perceived stress.

\section{DISCUSSION}

Significance of this study was to seek out the applicability of SCSD - 10 among diabetic patients in general population. Since long it was argued that a psychometrically evaluation reflects the global measure of perceived stress and whether it could provide valuable information about the relationship between pathology and stress \& compliance index. SCSD measures the extent to which situations in one's life are appraised as stressful and in level to achieve the probability of compliance.

In the objective line of this study, confirmatory factor analysis was conducted to explore the 2factor model. Results revealed a two-factor model structure measuring Perceived Stress and Perceived Compliance, which is consider as the novelty of the study. The current study findings show that the SCSD-10 is a reliable and valid instrument for the assessment of stress \& compliance among diabetic patients at community level. Gender difference to perceived stress was observed in this study, that is in the parallel with other studies in the literature $[10,12,14-15]$ stated that gender influences the appraisal process of stressful events in ways that are consistent with the differing socialization patterns of males and females. Matud (2004) [11] examined gender differences in stress and coping in a large sample (1566 women and 1250 men) between 18 and 65 years old, with different socio-demographic characteristics. The results of multivariate analysis of covariance, after adjusting for sociodemographic variables, indicated that the women scored higher than the men in chronic stress and minor daily stressors. Although there was no difference in the number of life events experienced in the previous 2 years, the women rated their life events as more negative and less compliant than the men.

The use of SCSD-10 with both researcher and counselors working with university students will obtain the data for the future implication and baseline applications. However, this instrument can be used with the general population; hence this study is one of its own kind with the subjects of pathological disorder (diabetes mellitus) from general population.

\section{Limitation of the study}

The major gap in this type of cross-cultural research methodology on health outcomes is that most of the measurements were developed in English-speaking countries and there are relatively few measurements which have been properly constructed or appropriately translated and evaluated in non-English-speaking culture. Therefore, the adaptation of SCSD-10 will give the researcher the opportunity to conduct crosscultural studies related to the appraisal of stress 
in the society and other cultural or pathological variables. In future, it would be helpful to identify stressors and minimize non-compliance in the community in order to ensure healthy living.

\section{CONCLUSION}

Psychometric validation of Stress \& Compliance Scale for Diabetes (SCSD) shows that the SCSD-10 is a reliable tool for assessing stress and compliance among diabetics living in a community. A higher stress level with least compliance is identified among the females compared to male diabetic patients. Overall, the whole cohort has high stress and least compliance.

\section{REFERENCES}

1. International Diabetic Federation (IDF) (2006). Diabetes Atlas. [Accessed 2 July 2010]. http://www.diabetesatlas.org/content/internationaldiabetes-federation.

2. Mokdad AH, Ford ES, Bownman BA, Dietz WH, Vinicor F, Bales VS, Marks JS. Prevalence of obesity, diabetes and obesity-related health risk factors, 2001. JAMA 2003; 289(1): 76-79.

3. Aguilar-Zavala $H$, Eugenia Garay-Sevilla M, Manuel Malacara J, Leticia Perez-Luque E. Stress, inflammatory markers and factors associated with patients with type-2 diabetes mellitus. Stress and Health 2008; 24(1): 49-54, DOI: 10.1002/smi.1162

4. Stephanie P Farrell, Anthony A Hains, W. Hobart Davies, Philip Smith, Elaine Parton. The impact of cognitive distortions, stress, and adherence on metabolic control in youths with Type 1 diabetes. J Adolesc Health., 2004; 34: 461-467

5. Marin TJ, Martin TM, Blackwell E, Stetler C, Miller GE. Differentiating the impact of episodic and chronic stressors on hypothalamic-pituitary adrenocortical axis regulation in young women. Health Psychology, 2007; 26(4): 447-455.
6. Seiffge-Krenke I., Stemmler M. Coping with everyday stress and links to medical and psychosocial adaptation in diabetic adolescents. J Adolesc Health. 2003; 33(3): 180-188.

7. Spiess K, Sachs G, Moser G, Pietschmann $P$, Schernthaner G, Prager R. . Psychological moderator variables and metabolic control in recent onset Type I diabetic patients: A two year longitudinal study. J Psychosom Res., 1994; 38(3): 249-258.

8. Stewart-Knox BJ. Psychological under pinnings of metabolic syndrome. Proceedings of the Nutrition Society, 2005; 64: 363-369.

9. Akerstedt T, Kecklund G, Axelsson J. Impaired sleep after bedtime stress and worries. Biological Psychology. 2007; 76: 170-173.

10. Martins RC. Andersen ML, Tufi KS. The reciprocal interaction between sleep and type 2 diabetes mellitus: Facts and perspectives. Braz $\mathrm{J}$ Med Biol Res, 2008; 41(3): 180-187.

11. Matud MP. Gender differences in stress and coping styles. Personality and Individual Differences, 2004; 37(7): 1401-1416.

12. Bentler SJ. Application of covariance structure modeling in psychology: Cause for concern. Psychological Bulletin, 1990; 107(2): 260-273.

13. Compas B, Grant K. Ey S. Psychosocial stress and child and adolescent depression: Can we be more specific? In W.M. Reynolds \& H.F. Johnston (Eds.) Handbook of depression in children and adolescents 1994; (pp. 509-523). New York: Plenum Press.

14. Lazarus RS. Folkman S. Stress, appraisal, and coping. New York, NY: Springer Publishing Company, 1984.

15. Herman-Stabl MA, Stemmler M, Petersen AC. Approach and avoidant coping: Implications for adolescent mental health. J Youth Adolesc, 1995; 24: 649-655.

16. Department of Statistics Malaysia: Population and housing census of Malaysia 2010, Economic briefing to the Penang state government 2010, 5(11): 5-6.

17. Savasir I. Problems and solutions in scale adaptation. Turkish journal of Psychology, 1994; 9(33), 27-32.

18. Spiegel K, Knutson K, Leproult R, Tasali E, Van Cauter E. . Sleep loss: A novel risk factor for insulin resistance and Type 2 diabetes. J Appl Physiol ,2005; 99: 2008-2009 